\title{
Mudanças de técnicos no futebol: estudo com o Campeonato Paulista
}

http://dx.doi.org/10.11606/1807-5509201800020199

\author{
Bruno Klinke MONTEIRO* \\ João Guilherme Cren CHIMINAZZO** \\ Fabrício Boscolo DEL VECCHIO ${ }^{* * *}$
}

* Faculdades

Integradas

Metropolitanas de

Campinas, Campinas, SP, Brasil.

** Faculdade de

Educação Física

Universidade Estadual de Campinas,

Campinas, SP, Brasil

*** Escola Superior

de Educação Física,

Universidade Federal

de Pelotas, Pelotas,

RS, Brasil.

\section{Resumo}

0 objetivo do presente estudo foi analisar o efeito das mudanças de técnicos na classificação final das equipes de futebol. Foram analisadas as súmulas oficiais dos jogos de 60 equipes que disputaram o Campeonato Paulista de Futebol de 2009 nas três divisões. A análise dos dados empregou estatística descritiva, correlação de Spearman e regressão linear. Os resultados apontaram para total de 88 trocas de técnicos durante 0 campeonato, sendo 24 na série $A 1,36$ na série $A 2$ e 28 na série $A 3$. Apenas na série $A 1$ houve relação significante $(r h o=0,61 ; p=0,003)$ entre a troca de técnicos e a classificação final, sendo que a troca de técnicos determinou em $37 \%$ a classificação final $(F=10,48 ; p=0,005)$. Apesar da troca de técnicos ter sido evento frequente, para as séries $A 2$ e $A 3$ a mesma não teve relação com a classificação da equipe na competição (respectivamente $r^{2}=0,12 ; F=2,42 ; p=0,13$ e $r^{2}=0,01 ; F=0,06 ; p=0,81$ ). Conclui-se que, na série A1 do Campeonato Paulista de Futebol de 2009, quanto menor o número de trocas de técnicos, melhor foi a classificação competitiva das equipes.

Palavras-Chave: Futebol; Troca de técnico; Classificação Final; Esporte.

\section{Introdução}

No cenário brasileiro, o futebol atravessa momento de reestruturação em sua organização e, consequentemente, há interesse de participação mais ativa do capital financeiro mundial neste mercado ${ }^{1-2}$. Os responsáveis pelo desempenho dentro do campo são os jogadores e a comissão técnica, a qual, em equipes profissionais, é composta por técnico, auxiliar técnico, preparador físico, preparador de goleiros, massagista, médico, fisioterapeuta, fisiologista e nutricionista ${ }^{3}$. O técnico é o profissional que coordena as açôes técnicas e táticas e analisa pontos fortes e fracos de outras equipes na tentativa de obtenção do melhor resultado ${ }^{4}$. Com as pressôes das torcidas e dos próprios dirigentes em busca constante de resultados melhores, cria-se instabilidade na profissão de técnico de futebol ${ }^{5}$. Assim, o processo de contratação e demissão deste profissional é um fenômeno drástico, mas frequente, e se relaciona com o baixo desempenho da equipe durante a competição ${ }^{6}$. Em contrapartida, no futebol não se conhecem dados da relaçáo entre mudança de técnico e sucesso competitivo no contexto brasileiro.

Com esta alta rotatividade nas trocas, buscamse tentativas para melhorar o rendimento, pois o técnico é visto, pelos torcedores e gestores do futebol, como o responsável pelo desempenho e, consequentemente, pelo sucesso da equipe ${ }^{7}$. As mudanças neste cargo também têm o objetivo de amenizar as pressóes realizadas pelos torcedores e desviar a atençáo dos mesmos e da mídia em relaçáo aos maus resultados obtidos ${ }^{2,8}$. No entanto, entre as diferentes investigaçóes conduzidas, não se tem consenso sobre a efetividade desta estratégia no êxito esportivo. Embora alguns estudos tenham 
observado melhorias de curto prazo ${ }^{9,10}$, outros trabalhos não registraram benefícios na adoção deste tipo de decisão ${ }^{11}$. Adicionalmente, parece náo existirem resultados distintos se consideradas as diferentes divisóes competitivas, apesar de times da terceira divisão apresentarem tendência de melhoras superiores a times da segunda e da primeira divisão quando ocorrem trocas de técnicos na Bélgica ${ }^{10}$.

\section{Método}

\section{Amostra}

Consideram-se, como sujeitos do estudo, 60 equipes de futebol profissional do estado de São Paulo, sendo 20 times de cada uma das séries A1, A2 e A3 do Campeonato Paulista de Futebol Masculino do ano 2009.

Esta competição, dividida em três séries (A1, A2 e A3), tem o seguinte modo de disputa: a série A1 é composta por 20 equipes sendo que, na primeira fase, elas se enfrentam em turno único (19 jogos), no qual as quatro últimas colocadas são rebaixadas para a série $\mathrm{A} 2$ e as quatro primeiras colocadas passam para a fase final, a qual é disputada em eliminatória simples com dois jogos cada. Já nas séries A2 e A3 são 20 equipes em cada, as quais disputam em turno único (19 jogos) a primeira fase. As quatro equipes piores classificadas da série A2 são rebaixadas para a série $\mathrm{A} 3$, bem como as quatro piores da série $\mathrm{A} 3$ são rebaixadas para a quarta divisão. Para a segunda fase, dispóem-se as oito equipes melhores colocadas de ambas as séries, as quais são divididas em dois grupos e se enfrentam em turno e returno, classificandose as duas melhores equipes de cada grupo para a semifinal. Por fim, as duas equipes vencedoras das semifinais chegam à final.

\section{Instrumentos e procedimentos de coleta e registro dos dados}

Para explorar as comunalidades entre as variáveis classificação final de cada equipe ao término do campeonato e a quantidade de técnicos que cada uma delas teve ao longo da competição, foram analisadas as súmulas de todas as partidas das séries $\mathrm{A} 1, \mathrm{~A} 2 \mathrm{e}$ A3 do Campeonato Paulista de Futebol Masculino categoria profissional - do ano 2009, a partir de pesquisa descritiva correlacional.
Olhando para as constantes alteraçóes destes profissionais que ocorrem antes, durante e após os campeonatos, bem como para a ausência de estudos acerca desta temática em âmbito nacional, este estudo teve como objetivo investigar as mudanças de técnicos de futebol no Campeonato Paulista de Futebol Masculino das séries A1, A2 e A3, no ano 2009, e suas relaçôes com as classificaçóes finais das equipes.
A coleta de dados foi realizada da mesma forma para todas as equipes e divisóes apresentadas. Sistematicamente, foram acessadas as bases de dados da Federação Paulista de Futebol e registrado o técnico relatado nas súmulas de cada equipe. Essas súmulas estavam disponíveis no endereço virtual da Federaçáo Paulista de Futebol (site oficial: www.futebolpaulista. com.br) ${ }^{12}$. Por meio destas súmulas foi verificado, a cada rodada, se houve troca de técnicos e, em caso de alteração, as informações foram inseridas em planilhas eletrônicas especificamente formatadas para este fim.

Para manter o anonimato das equipes e pelo fato do objeto de estudo estar disponível livremente no meio virtual, a pesquisa é dispensada de submissáo ao Comitê de Ética em Pesquisa e não se aplica solicitação de assinatura do respectivo Termo de Consentimento Livre e Esclarecido.

As classificaçóes finais das equipes também foram registradas a partir do acesso às bases de dados da Federação Paulista de Futebol.

\section{Análise estatística}

Após os dados serem tabulados, realizou-se o teste de normalidade a partir da prova de ShapiroWilk. Nela, verificou-se que, para as três divisóes, os dados referentes às trocas de técnicos exibiram distribuição não-normal ( $\mathrm{W}=0.53 ; p=0.03$ ). Assim, para estatística descritiva, empregou-se mediana e semiamplitude interquartílica (percentis 50 [25-75]). Para a comparação do número de trocas de técnicos, segundo divisáo (A1, A2 e A3), foi usada análise de variância não-paramétrica de Kruskal-Wallis. Para o teste de correlação entre classificação final (variável ordinal) e número de trocas de técnicos (variável discreta), foi empregada a correlação de Spearman (rho), e o coeficiente de 
determinação foi calculado a partir de equaçóes lineares de regressão, considerando o modelo stepwise, em cada uma das divisóes. Assumiu-se $5 \%$ como nível de significância estatística.

\section{Resultados}

A quantidade de trocas de técnicos entre os times das divisóes A1, A2 e A3 é apresentada na TABELA 1. Nela, observa-se mediana de duas modificaçóes destes profissionais ao longo do campeonato por equipe, sem diferenças significantes entre divisóes $(H=1,41, p=0,49)$.

Sobre a série A1, a competiçáo foi realizada de janeiro a maio de 2009 e se registraram 24 trocas de técnicos sendo que, nos meses de fevereiro e março, ocorreram $83,2 \%$ do total das mudanças. $\mathrm{Na} \mathrm{A} 2$, a competiçáo foi realizada de janeiro a junho de 2009 e se computaram 36 trocas, com o mês de março apresentando $44,4 \%$ do total. Por fim, na A3 a competiçáo foi realizada de janeiro a junho de 2009 e se somaram 28 trocas de técnicos, com $35,7 \%$ das alteraçóes ocorridas no mês de março.

Quanto às correlaçóes, observam-se valores positivos significantes para a primeira divisão $(r h o=0.61, p=0.003)$, o que não foi registrado nas demais (FIGURA 1, painéis B e C). Ou seja, na série $\mathrm{A} 1$, quanto menor o número de trocas de técnicos, melhor foi a classificação competitiva das equipes ao final do campeonato. Especificamente acerca da determinação da classificação final frente ao número de trocas de técnicos, observa-se que, na primeira divisão, troca de técnicos determinou em $37 \%$ a classificação final $(\mathrm{F}=10,48 ; \mathrm{p}=0,005)$. Para as séries $\mathrm{A} 2 \mathrm{e} \mathrm{A} 3$ a troca de técnicos náo teve relação com o êxito da equipe na competiçáo (respectivamente $r^{2}=0,12 ; F=2,42 ; p=0,13$ e $\left.r^{2}=0,01 ; F=0,06 ; p=0,81\right)$.

Por fim, considerando todos os clubes das três divisóes, a troca de técnicos ao longo do campeonato contribuiu com $8 \%$ na determinação da classificação final no Campeonato Paulista de 2009, sendo que cada troca melhorou pouco mais de uma posição $(\beta=1,5[\mathrm{IC} 95 \%=0,28-2,7] ; \mathrm{F}=6,04 ; \mathrm{p}=0,02)$.

TABELA 1 - Medidas descritivas referentes ao número de trocas de técnicos no Campeonato Paulista de Futebol de 2009, segundo divisão competitiva $(n=60)$.

\begin{tabular}{ccccc}
\hline & Primeira divisáo & Segunda divisáo & Terceira divisáo & Total \\
\hline Mínimo & 1 & 1 & 1 & 1 \\
$25 \%$ & 1,75 & 2 & 2 & 2 \\
\hline Mediana & 2 & 2,5 & 2 & 2 \\
$75 \%$ & 3 & 4 & 3 & 3 \\
\hline Máximo & 4 & 6 & 5 & 6 \\
\hline
\end{tabular}

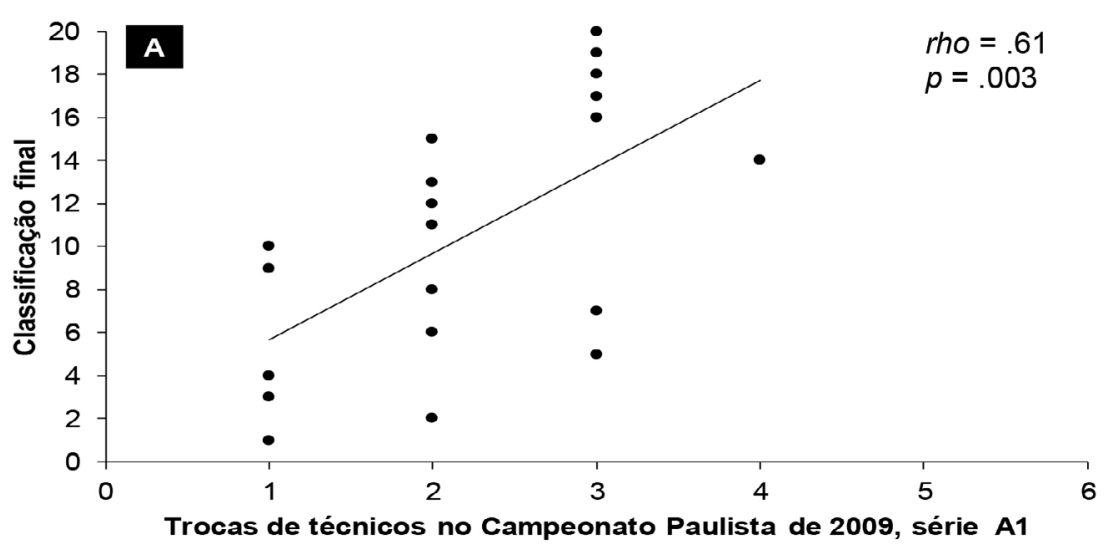



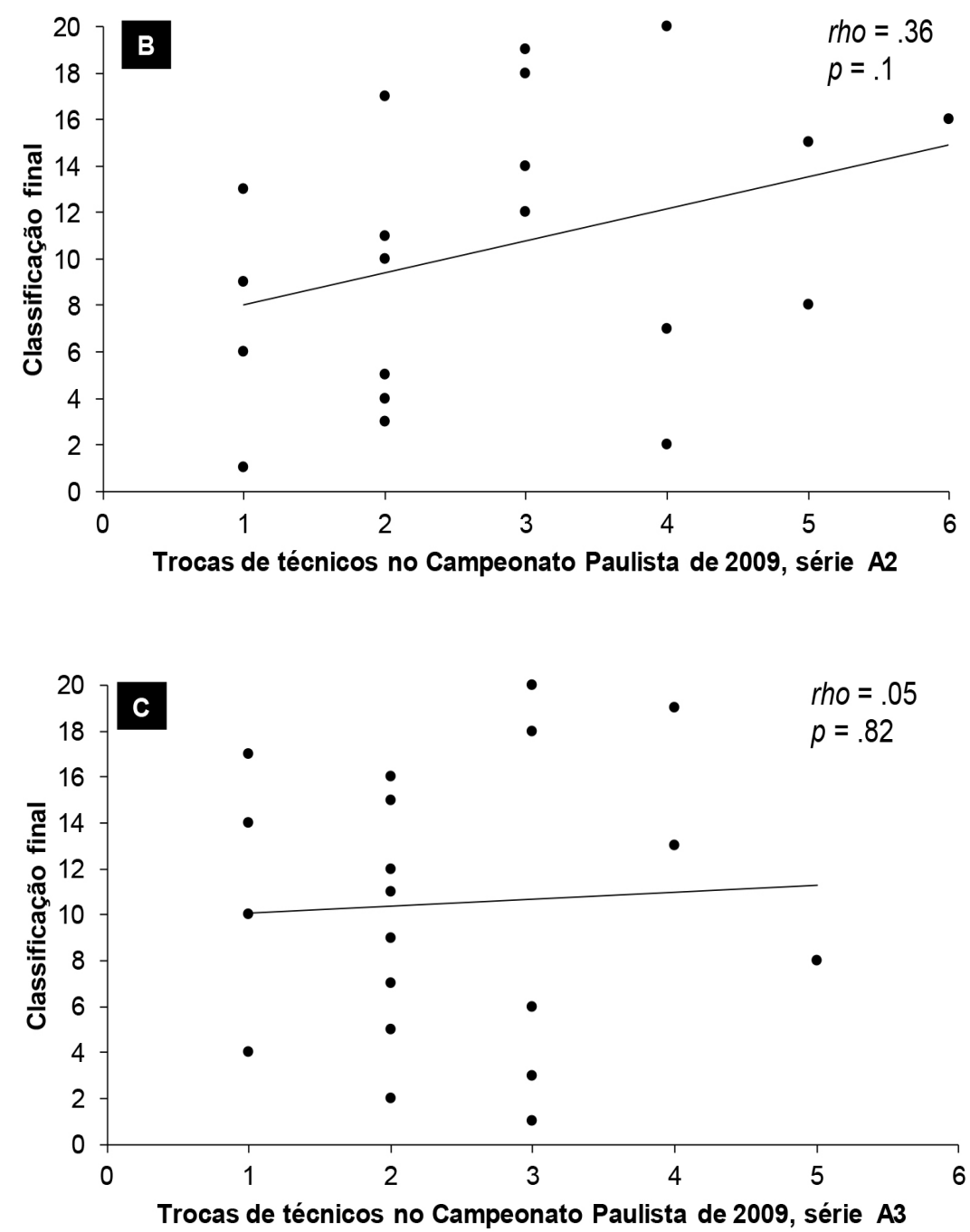

FIGURA 1 - Relações entre número de trocas de técnicos e classificação final no Campeonato Paulista de Futebol de 2009, segundo divisão competitiva (painel A: divisão A1, painel B: divisão A2, painel C: divisão A3).

\section{Discussão}

Este estudo analisou a quantidade de trocas de técnicos no Campeonato Paulista de 2009 e investigou seus efeitos na classificação final dos respectivos times. O principal achado do presente estudo foi a relação positiva significante entre o número de trocas de técnicos e a classificação final das equipes da série A1, ou seja, quanto menor a quantidade de trocas, melhor foi a classificação final obtida. No entanto, vale lembrar que este valor significante não expressa relação de causa-efeito, e que este evento só foi observado na série A1. Ao se considerarem todos os clubes, as trocas de técnicos explicaram aproximadamente $8 \%$ das classificaçôes finais, sendo que cada troca prejudicou o time em 1,5 posição na classificação final.
Destaca-se que ocorreram, aproximadamente, duas trocas nos times ao longo de uma temporada, mas houve equipes que trocaram até seis técnicos na temporada. De modo geral, nas três divisóes, houve maior frequência de trocas entre seis e oito semanas após o início do campeonato, possivelmente em decorrência de resultados inferiores aos esperados para o início da temporada competitiva e pressão da comunicação midiática ${ }^{13}$. Adicionalmente, reconhece-se que a carreira do técnico de futebol é altamente desafiante e envolta por um ambiente muito competitivo ${ }^{7}$. Tal cenário, de certo modo, minimiza o impacto negativo destas demissóes sucessivas $^{6}$ e mantém o interesse da mídia pelo 
espetáculo e pelo desempenho elevado das equipes ${ }^{13}$, porém gera um ambiente de trabalho estressante com elevados níveis de ansiedade?.

O quadro de insucesso competitivo, a expectativa de êxitos futuros baseada em resultados pregressos e a pressão da mídia, gestores e torcedores resultam na troca do técnico, pressupondo-se que tal mudança reverta a situação para uma condição melhor ${ }^{8}$. No entanto, os dados obtidos na literatura são bastante controversos, independentemente da modalidade considerada ${ }^{6,8,14}$. Investigaçóes de 1989 a 2003, derivadas de times da National Hockey League (NHL), dos Estados Unidos da América, indicam que a troca de técnicos no meio da temporada tende a aumentar o desempenho da equipe, pelo menos, nos jogos subsequentes ou, às vezes, até o final das competiçóes, especialmente em situaçóes nas quais técnicos menos experientes foram substituídos por técnicos mais experientes ${ }^{15}$. Na presente investigação, com o futebol, registrou-se comportamento diferenciado, com a maior parte das trocas ocorrendo nos primeiros meses de competição, possivelmente devido às pressóes dos diferentes setores da sociedade em busca do êxito em curto prazo ${ }^{6,13}$, e isto foi especialmente evidente na série A1.

Como efeito de curto prazo, uma análise de 8.392 jogos belgas de futebol registrou que, após a troca de técnicos, o sucesso competitivo tende a melhorar em quatro jogos subsequentes ${ }^{10}$. Análise de sete temporadas do campeonato Belga de futebol indicou que, se o posicionamento de novos técnicos eleva a qualidade competitiva das equipes, as mesmas conseguem obter melhores posicionamentos na classificação final ${ }^{10}$. Vale lembrar, ainda, que uma nova proposta de organização construída por diversas áreas do clube (diretoria, comissão e jogadores) e planejamento de médio-longo prazo para consolidação de um modelo de jogo, que requer tempo, são fatores que levam a instituição a alcançar seus objetivos e se constituem como procedimentos mais resolutivos para o seu desenvolvimento. Por isso, indica-se que a manutenção dos técnicos pode ser relevante para permitir que os mesmos consigam desenvolver seu trabalho.

$\mathrm{Na}$ série A do futebol italiano não foram observados efeitos positivos da troca de técnicos no desempenho final das equipes, com exceção do número de gols marcados ${ }^{11}$. Uma análise da liga inglesa de futebol de 1972 a 1993 registrou maior frequência de trocas de técnicos nas divisóes inferiores ${ }^{16}$, o que não foi observado na presente investigação. Inclusive, naquela oportunidade, observou-se efeito prejudicial imediatamente após este tipo de procedimento ${ }^{16}$. Novamente, quanto aos dados da presente investigação, times que exibiram maior número de trocas ao longo da temporada terminaram o campeonato em piores posiçóes $(r h o=0.61)$, o que tende a corroborar com os achados do estudo com a liga inglesa.

Um dos motivos que pode explicar o processo de troca de técnicos está associado com o modo como eles gerenciam os jogadores. Ao considerar os treinadores do Campeonato Brasileiro série A/2005, estudo observou que estes profissionais utilizavam mais a liderança autoritária e os aspectos de treinoinstrução e reforço para comandarem suas equipes ${ }^{4}$, o que pode ser mal interpretado pelos atletas. De modo geral, técnicos de sucesso expressam comportamento instrucional frequente, uso sucessivo de elogios aos jogadores e emprego do silêncio como estratégia técnica consciente ${ }^{17}$. Adicionalmente, já se constatou que estes profissionais realizam intervençóes com conteúdo prioritariamente técnico, sobretudo de caráter ofensivo, quando os jogadores estão em ação. Complementarmente, estas instruçóes são genéricas, individuais, predominantemente auditivas e com reforço positivo. Neste contexto, destaca-se que treinadores formados em Educação Física recorrem mais ao questionamento geral e específico do que técnicos sem formação, concedendo mais espaço aos jogadores para compreensão e problematização dos conteúdos de aprendizagem ${ }^{18}$. Ainda com vistas a aumentar o êxito profissional, técnicos têm empregado diferentes estratégias, como análise notacional manual, uso de computadores para registro de eventos e análises com vídeo ${ }^{19,20}$. Ainda assim, percebe-se um modelo de gestão amador por parte dos profissionais que trabalham com o futebol e, com isso, os mesmos desconhecem pontos importantes do processo de treinamento ${ }^{21}$.

Como limitação do presente estudo, destaca-se a dependência da veracidade dos dados apresentados nas diferentes súmulas analisadas. No entanto, ressalta-se que este é o instrumento oficial, inclusive com poder legal. Para estudos futuros, recomendam-se pesquisas que investiguem a associação entre perfil técnico e rotatividade profissional, assim como analisem os motivos da frequência de troca de técnicos em âmbito nacional. Isto se dá, pois, aparentemente, estabeleceu-se no universo do futebol o costume de se efetuarem trocas quando o time apresenta resultados negativos, associando-se a troca com melhora de desempenho, o que foi refutado pelo presente estudo. Adicionalmente, investigaçóes devem avaliar o impacto 
deste procedimento, e identificar variáveis relacionadas à permanência de treinadores em uma mesma equipe.

Com a presente investigação, concluiu-se que, de modo geral, trocas de técnicos determinaram negativamente a classificação final em $8 \%$. Na série A1, este efeito foi mais pronunciado (37\%) e, nas divisōes inferiores, a classificação final das equipes não foi determinada pela troca de técnico. Sugere-se que, contrariamente à opção de troca de técnico, opte-se pela manutençáo do mesmo, proporcionando maior tempo para desenvolvimento e formação de modelo de jogo sólido. Futuramente, seria interessante analisar outros fatores que possam afetar a classificação final das equipes, tais como: condições de treinamento e logística de viagens. Por fim, destaca-se que, atualmente, existem alteraçôes no calendário do futebol brasileiro, as quais permitem maior tempo de trabalho na prétemporada, o que ajudaria a evitar maior número de troca de técnicos no início da temporada decorrente de insucessos nos resultados das partidas.

\section{Abstract \\ Coaches changes in soccer: study with the "Campeonato Paulista"}

The purpose of the present study was to analyze the effects of coach turnover in the final classification of soccer teams. Data were obtained from all games official overviews of 60 teams that played in the 2009 Paulista Football Championship in the 3 divisions. Data analysis employed descriptive statistics, Spearman correlation and linear regression. The results pointed to a total of 88 coaches exchange during the championship, with 24 in the A1 division, 36 in the A2 division and 28 in the A3 division. Only in the A1 division, there was a significant relationship ( $r h o=0.61, p=0.003$ ) between the coach exchange and the final classification, so being determined $37 \%$ the final classification $(F=10.48, p=0.005)$. Although the coach exchange was a frequent event, for the $A 2$ and $A 3$ division the coach exchange had no relation to the team's classification in the competition ( $r 2=0.12, F=2.42, p=0.13$ and $\left.R^{2}=0.01, F=0.06, p=0.81\right)$. It is concluded that, in the division A1 of the Paulista Football Championship of 2009, the smaller the number of coaches exchange, the better was the competitive classification of the teams.

KEYWORDS: Soccer; Coach exchange; Final classification; Sport.

\section{Referências}

1. Marturelli Junior M. A organização de trabalhos de treinadores de futebol: estratégias de ação e produtividade de equipes profissionais [dissertaçâo]. Florianópolis (SC): Universidade Federal de Santa Catarina; 2002.

2. Satterlee T. Making soccer a 'kick in the grass': the media's role in promoting a marginal sport, 1975-1977. Int Rev Sociol Sport. 2001;36(3):305-17.

3. Trapattoni G. Coaching high performance soccer. Spring Ciry, PA: Reedswain; 1999.

4. Costa IT, Samulski DM. O perfil de liderança de treinadores de futebol do Campeonato Brasileiro Série A/2005. Rev Bras Educ Fís Esporte. 2006;20(3):175-84.

5. Marturelli Junior M, Oliveira AL. Treinadores de futebol de alto nível: as evidentes dificuldades que cercam a produtividade destes profissionais. IX Simpósio Internacional Processo Civilizador; 2005 Nov 24-26; Ponta Grossa, BR. Curitiba: Cefet; 2005.

6. Koging RH. An econometric evaluation of the effect of firing a coach on team performance. Applied Economics. 2003;35:555-64.

7. Jones RL, Armour KM, Potrac P. Constructing expert knowledge: a case study of a top-level professional soccer coach. Sport Educ Soc. 2003; 8(2): 213-29.

8. Salomo S, Teichmann K. The relationship of performance and managerial succession in the German Premier Football League. European Journal for Sport Management. 2000; 7: 99-119.

9. Frick B, Carlos PB, Joachim P. Analysing head coach dismissals in the German "Bundesliga" with a mixed logit approach. Eur J Oper Res. 2010; 200:151-159.

10. Balduck AL, Buelens M, Philippaerts R. Short-term effects of midseason coach turnover on team performance in soccer. Res Q Exerc Sport. 2010; 81(3):379-83. 
11. Paola M, Scoppa V. The effects of managerial turnover: evidence from coach dismissals in Italian soccer teams. J Sports Econom. 2012;13(2):152-68.

12. Federação Paulista de Futebol [Internet]. São Paulo: Federação Paulista de Futebol [cited 2009 Jun 24]. Available from: http:// www.futebolpaulista.com.br.

13. Lee FLF. Spectacle and fandom: media discourse in two soccer events in Hong Kong. Sociol Sport J. 2005; 22(2):194-213.

14. McTeer W, White PG, Persad S. Manager/coach mid-season replacement and team performance in professional team sport. J Sport Behav. 1995;18(1):58-68.

15. White P, Persad S, Gee CJ. The effect of mid-season coach turnover on team performance: the case of the National Hockey League (1989-2003). Int J Sports Sci Coach. 2007;2(2):143-152.

16. Balduck AL, Prinzie A, Buelens M. The effectiveness of coach turnover and the effect on home team advantage, team quality and team ranking. J Appl Stat. 2010;37(4):679-89.

17. Cushion CJ, Jones RL. A systematic observation of professional top-level youth soccer coaches. J Sport Behav. 2001;24(4):354-76.

18. Mesquita I, Farias C, Oliveira G, Pereira F. The pedagogical content intervention of the football coach. Rev Bras Educ Fís Esporte. 2009;23(1):25-38.

19. Hammond J, Perry J. A multi-dimensional assessment of soccer coaching course effectiveness. Ergonomics. 2005;48(11-14):1698-710.

20. James N. The role of notational analysis in soccer coaching. Int J Sports Sci Coach. 2006;1(2):185-198.

21. Reis LJL. Perfil do gestor desportivo de clubes de futebol - uma proposta de modelo de formação [dissertação]. Lisboa (PT): Universidade de Lisboa, Faculdade de Motricidade Humana; 2016.

ENDEREÇo
João Guilherme Cren Chiminazzo Rua Valentina Penteado de Freitas, 482 Parque das Universidades

13086-140 - Campinas - SP - BRASIL e-mail: chiminazzo@hotmail.com
Recebido para publicação: 10/10/2014

$1^{\text {a }}$ Revisão: 13/02/2017

Aceito: 23/03/2016 
